\title{
Digital Technologies as Basis for Archaeological Heritage Preservation: 3D-Modeling for Geoinformation System
}

\author{
Marina Grickevich, Irina Andreeva ${ }^{1}$, Alexander Belitskii, and Alexander Khoperskov* \\ Volgograd State University, 400064 Volgograd, Russia
}

\begin{abstract}
Modern information technologies provide unique opportunities of cultural heritage preservation and creation of new software tools analyzing archaeological data. In the current article, we discuss the features of designing services of the system supplying work with spatially distributed archaeological data by example of the specialized geoportal implementation at Volgograd State University. The design of the database with geospatial reference supported by the geoinformation system has been considered as well. A set of services for creation, visualization and publishing of 3D models is described. Our approach allows combining a digital terrain model with a 3D model of the archaeological excavation.
\end{abstract}

\section{Introduction}

Among the historical sciences, archeology occupies a special place by two reasons. It is a source of the overwhelming share of artifacts that is practically the only one for preliterate periods. However, the essential artifacts characteristics are not preserved in the excavations process since the burial ground, burial, burial mound are destroyed as an interconnected complex of historical objects and landscape including the soil layers, spatial arrangement of individual elements relative to each other, and precise georeference. Even the detailed descriptions, photos and video filming do not finally solve the problem.

The most valuable items arrive to museums and specialized scientific centers, but large number of less significant items are lost with the time. The situation with the preservation of excavated buildings, fortresses, monuments of architecture becomes more and more unfavorable. We already partially or completely have lost the significant share of the constructions which had belonged to the great ancient states and societies. Besides natural destruction due to earthquakes, landslides, floods, acid precipitation and other natural disasters $[1,2,3]$ we also observe vandalism especially in the war zones in Afghanistan, Iraq, Syria, Yemen and other countries. The well-known examples of loss are the Giant Buddhas of Bamiyan in Afghanistan [4], Site of Palmyra [5], and archaeological values in Armed Conflict between Iraq and Kuwait [6]. Finally, even historical monuments included into the cultural heritage and transferred to the category of open-air museums were lost to humanity.

There are two directions of 3D modeling. The first one is the technologies of 3D-models building for subsequent 3D-printing which are actively developing. These models are applied for educational purposes, for replace and replicate museum exhibits, for research tasks related to the restoration of artifacts especially in anthropology and paleontology. The other direction is the 3D-models development utilized in digital form to the virtual museums establishment [7], demonstrations in Web, and like an element of databases in specialized geoinformation systems [8]. Taking into the account wide distribution of graphic materials in social networks and applications for the photos and video recordings sharing (Instagram, VK, Flickr, YouTube, etc.), the new standards of information delivery are formed.

Thus, the clip-on thinking and the interactive means of individual artistic expression through the light become very important [9].

Our aim is the functionality description of the archaeological geoportal being developed at Volgograd State University. The most important components of the web-resource are the specialized geoinformation system based on GISWebServer, the services for work with 3Dmodels, the digital elevation model (DEM), and the thematic electronic maps. Our software allows placing small-scale 3D-models of archaeological objects on the DEM.

\section{Information models}

\subsection{The geoportal services}

The main components and functions of the geoportal for archaeological and paleoanthropological research support are discussed in the current section. Figure 1 shows the common structure of the Web-resource. The central component is a specialized archaeological database. Its distinguishable feature is backing of diverse data of various types including textual, graphic, video

* Corresponding author: grickevich $@$,volsu.ru 
information. The database records also contain georeferences. The geoinformation system (GIS) provides work with spatial data. GIS allows visualizing and manipulating data about a cartographic object in an external database. The web interface grants remote access to spatial information by the cartographic GIS webservice, which implements navigation on the map, changes in its spatial scale, search and selection of an object on the map, and output of information about objects.

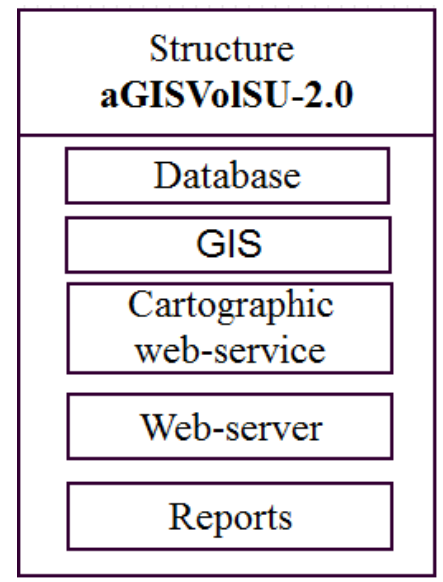

Fig. 1. The geoportal structure for archaeological research support.

There are three main types of geoportal users: Administrator / Editor, Volunteer and Simple User (Figure 2).

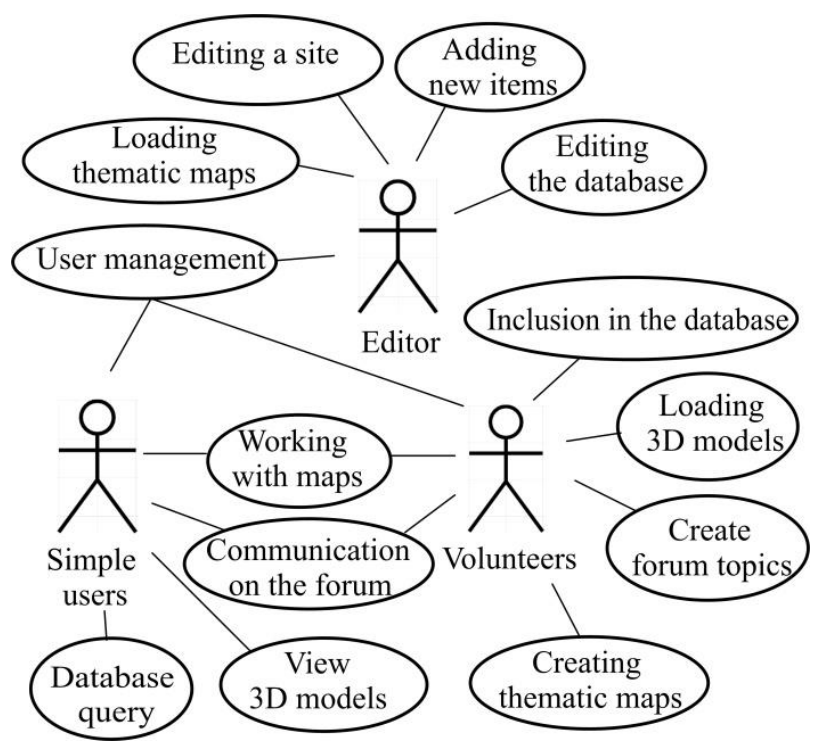

Fig. 2. The use of the case diagram.

A simple user does not have rights to edit materials and not need a login-password to work with the geoportal.

Simple users can only view articles, display reports, simulate thematic maps and print them out.

Volunteers should pass authorization to work with the system. In addition to the usual browsing and working, these Volunteers can create thematic maps, 3D models and forum threads, and fill out the database.
We also distinguish an additional type of a user, the "Editor", which has great capabilities within the given archaeological theme:

- adding a new object (name, geographical coordinates, epoch, type of object);

- creating and editing a list of categories, epochs, regions;

- customization of geoportal working areas;

- management of objects and database;

- setting up geoportal navigation.

The administrator can manage users, administer the database and the website, add new items and download thematic maps.

\subsection{Database Structure}

We used the standards for compiling scientific archaeological reports [10] designing the structure of the database. The information on archaeological objects in the database is subdivided into three large groups: ancient settlement, burial ground, artifact. We include the data on the open sheet, the head of archaeological works, the culture and the era of studied objects, stratigraphy, bibliography, etc. The important characteristics are the type of artifact with a description of its features, descriptions of the grave pit, the location of the skeleton, ancient garbage pit, weapons and ritual objects.

Characteristics of the skull and skeleton structure are included in a separate anthropological database. The result of combining of the anthropological and archaeological databases consists of 15 tables.

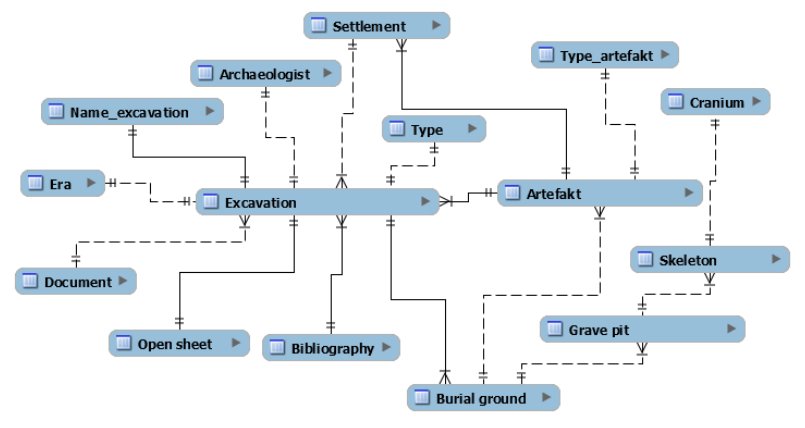

Fig. 3. The Database structure.

As an example of the ontology of the domain, let us consider the "Burial Ground" database, which includes basic concepts such as Excavation, Burial ground, Grave pit, Stratigraphy, Skeleton, Pit edge, Barrow, Burial, Shurf, Epoch, Culture, and etc. as an example of the domain ontology.

The excavation may contain several burial grounds being unearthed in their own way and this information should be stored in the database.

\subsection{GIS WebServer}

A distinctive feature of archeology and paleoanthropology is the spatial distribution of finds that are tied to the characteristics of the landscape. Archaeological GIS allows one to solve these problems and simplify the work on the systematization, processing and analysis of spatially distributed data using the built-in 
functional [8]. The server part of the geoinformation system is implemented using the GIS WebServer from "KB Panorama". This Web application is designed for the publication and integration in the Internet / Intranet of geospatial data, such as: electronic maps, data from logically related databases, reference information, spatial metadata databases and remote sensing data.

The application uses complex processing of static (background maps, raster images, matrices, satellite imagery) and dynamic data (real-time navigation and monitoring, spatial data bank, operational situation). The GIS WebServer provides an opportunity for web clients and desktop applications to work together with the same data, allowing them to be viewed and coordinated (Figure 4).

\subsection{Thematic maps}

Thematic maps are the most important source of information on the spatial location and characteristics of objects. Archaeological cartography with international conventional signs and legends began to form in the 19th century, but modern geoinformation technologies have become a powerful tool for spatial analysis $[8,11]$. In addition to the localization and description of objects, the identification of the spatial relationship between artifacts and the geographical landscape is a key problem in archaeological research. Thematic electronic maps are a convenient service for promptly entering data on new archaeological finds and their primary analysis. The ability to predict the location of objects is a promising area for future research.

We have created 18 thematic maps for publication on the geoportal within the framework of our project. Data for thematic maps are in the database, which allows you to distinguish various categories, for example, a site of ancient settlement, a burial ground, a single artifact. Our thematic maps refer to different epochs and cultures on the territory of the Great Eurasian Steppe: the Golden Horde, the Khazar Khaganate, the Sarmatians, the Scythians, the Mesolithic objects (See Figure 4).

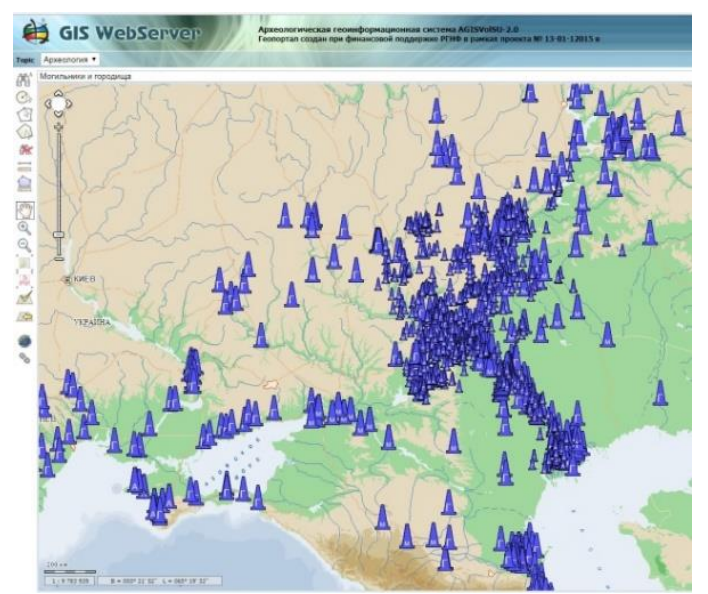

Fig. 4. Fragment of the thematic map on GIS WebServer.

\subsection{D-modelling}

The 3D model has many new features compared to traditionally used text descriptions, terrain plans and photographs. Sets of virtual 3D models at different times fix the process of archaeological work and retain many significant details for later analysis. An archaeological 3D-model is a surface that is built taking into account the terrain, which can be overlaid with a vector, matrix or raster map, also including objects with a 3D metric. On the digital model of the archaeological map, we must display both ground objects (above the surface level of the relief) and underground objects (below the relief level).

Figure 5 shows the plan of the Right-Bank Tsimlyansky ancient settlement according to S.A. Pletneva's reports [10] and the result of our modeling. This object was a fortress of Khazar Khaganate with the length of walls about $360 \mathrm{~m}$.
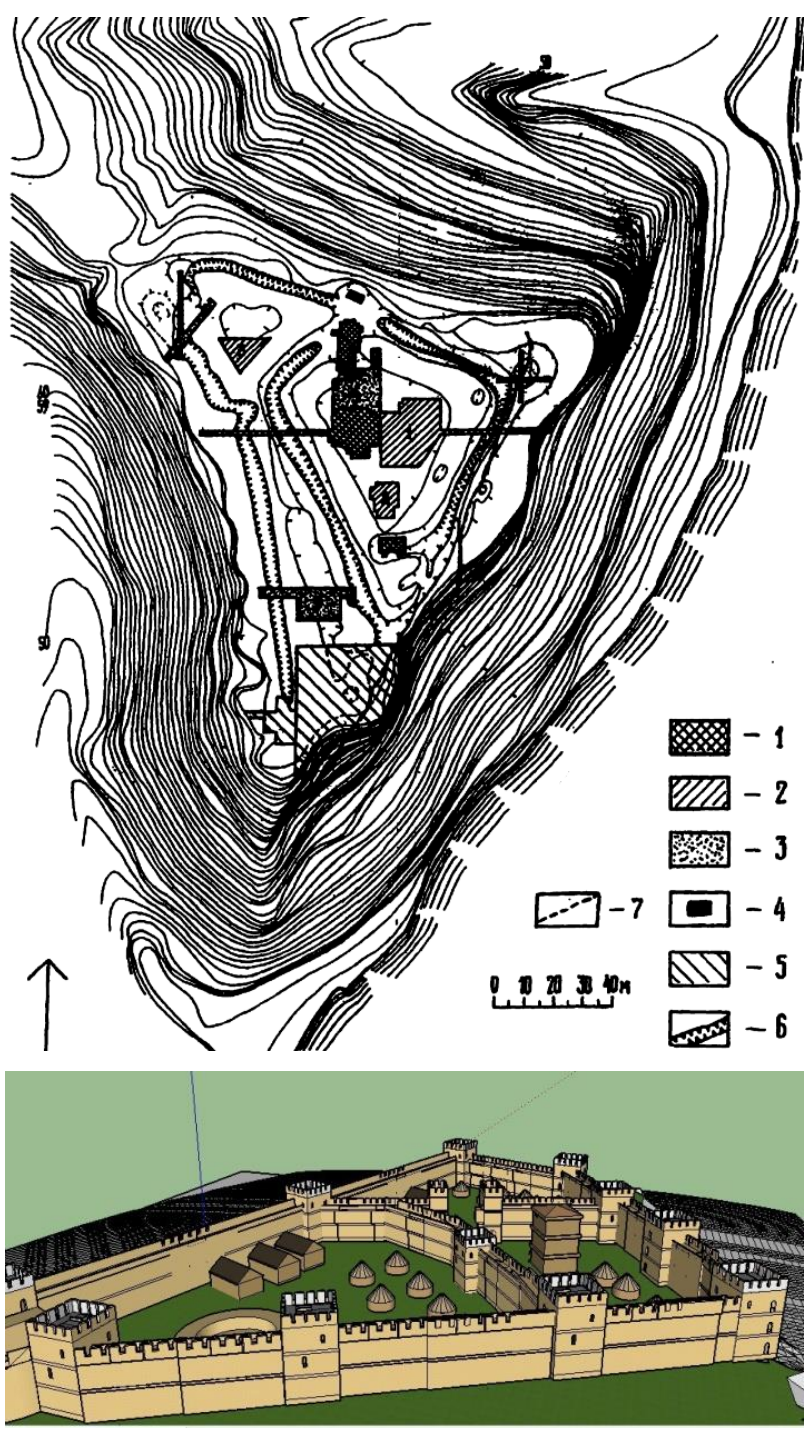

Fig. 5. Right-Bank Tsimlyansk ancient settlement: a) plan based on the results of archaeological excavations [10], b) 3Dmodel.

We implemented the geoportal module that provides storage of 3D models and work with 3D tools. The catalog of 3D-models includes subdirectories: Ancient Settlement, Burial Grounde, Artifact. We created the 3D viewer that allows you to view $3 \mathrm{D}$ reconstructions of an archaeological objec at various angles and with different 
scaling factors. 3D viewer supports *.dae and *.stl formats of models. Another tool is 3D-Maker, which models simple objects online and converts them into *.stl and *.vmm formats.

\subsection{Digital model of excavation and DEM}

Our service provides visualization of the 3D model of archaeological excavation in relation to the terrain, buildings, vegetation [12]. Figure 6 shows the location of burial grounds on the 3D landscape model (Krivosheev M.V., archaeological report).

The procedure of the "Digital Excavation Model" service is considered using the 3D model of one of the burial ground near the Aksay settlement in the Volgograd Region.

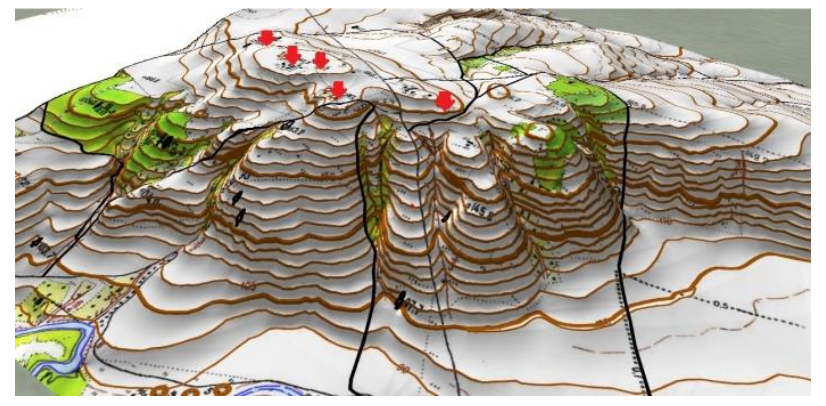

Fig. 6. 3D model of the area near the village of Kostarevo in the Volgograd region (red arrows show the location of the burial grounds).

The main stages of the creation of the digital excavation model are:

1) Creating the plan in scale 1:2000, which is most convenient for small excavations, burial grounds, artifacts with typical dimensions of $0.1-10$ meters.

2) Connecting the classifier.

3) Adding the bitmap image [13].

4) Creating a linear object with an indication of its dimensions.

5) Binding a bitmap image to a linear object by two points.

6) Localization of objects (artifacts), construction of a system of isolines of equal height.

7) Adding a matrix of heights for the given section of the map (Figure 7).

8) Creation of 3D-model with the help of geoinformation system $\mathrm{KB}$ «Panorama».

9) Expert testing of 3D model quality for different angles of view and distances from the observation point.

Figure 8 shows the result of this simulation.

\section{Conclusion}

We created the beta version of the geoinformation portal to support archaeological and paleoanthropological studies aGISVolSU-2.0. Information services allow you to work with a database,

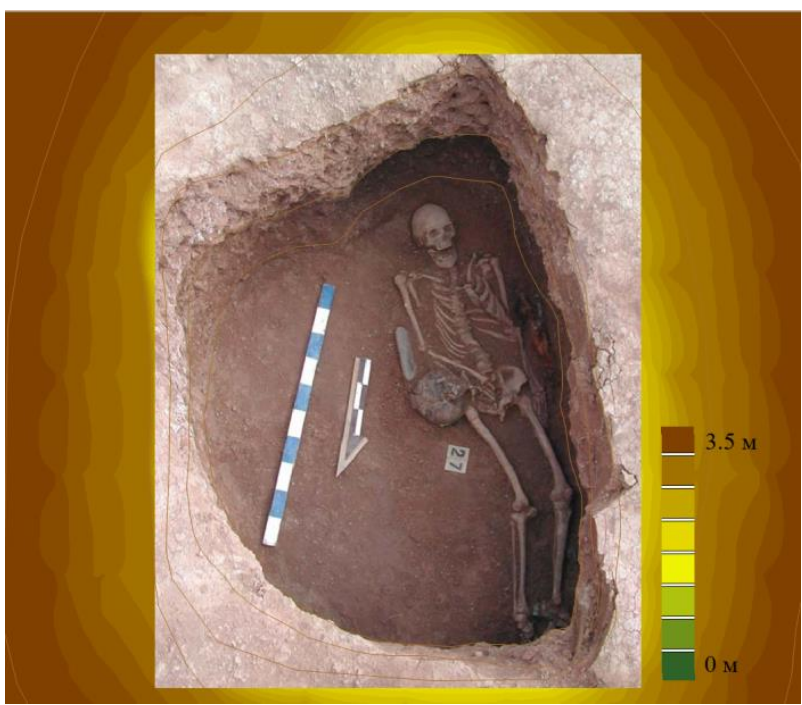

Fig. 7. The matrix of heights with raster of the archaeological excavation

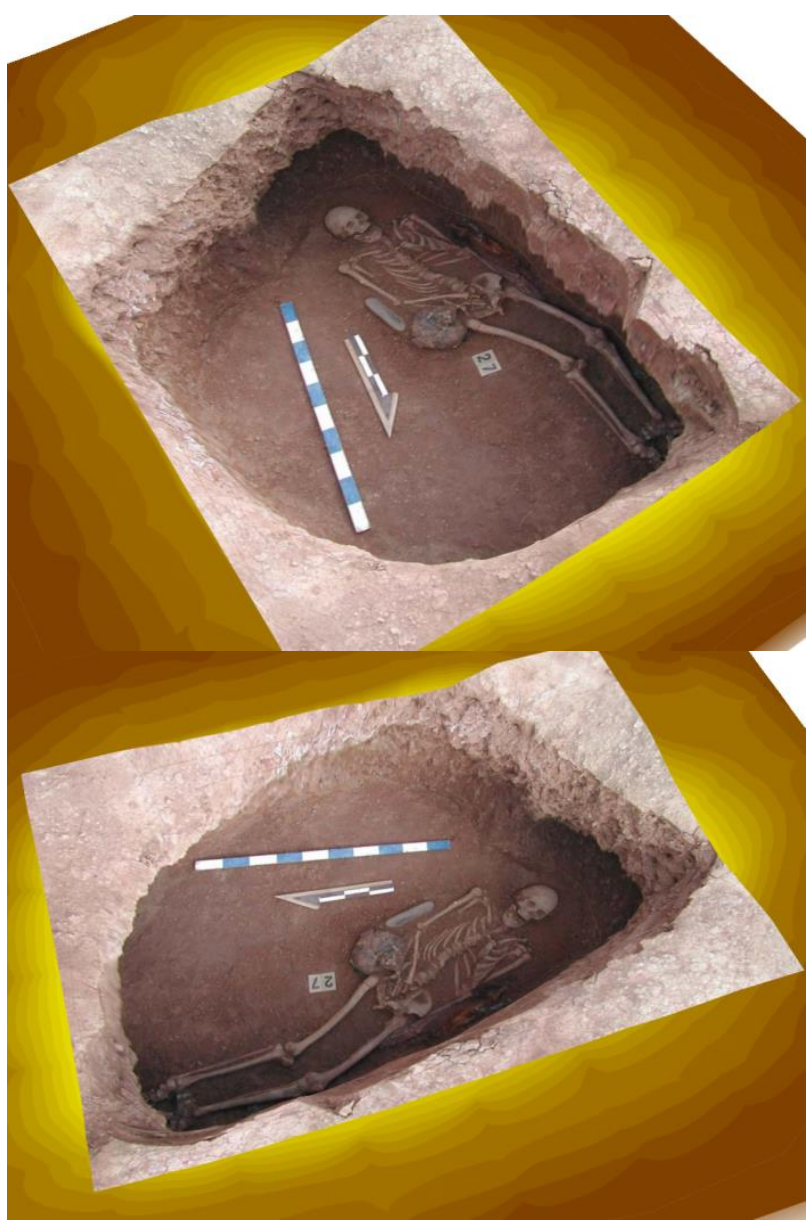

Fig. 8. 3D model of burial of Aksai II burial mound with the use of the digital excavation model.

thematic maps, 3D models of excavations and artifacts, a digital terrain model. GIS Web Server provides access to the database, the thematic maps and the tools for spatial analysis.

We created 18 thematic maps based on data on 1238 archaeological excavations, 3D models for the RightBank Tsimlyanskoye ancient settlement, Sarkel-Belaya 
Vezha, excavation of the burial ground "Lobanov's Shel", ancient settlement Uvek.

The authors are thankful to the Ministry of Education and Science of the Russian Federation (project No. 2.852.2017/4.6).

\section{References}

1. K. Weise, D. Gautam, H. Rodrigues, Response and Rehabilitation of Historic Monuments after the Gorkha Earthquake. Impacts and Insights of the Gorkha Earthquake, 65 (2018)

2. B. Usmanov, I.C. Nicu, I. Gainullin et al., Journal of Coastal Conservation 22, 417 (2018)

3. M.D. Howland, I.W.N. Jones, M. Najjar, et al., Journal of Archaeological Science 90, 62 (2018)

4. A. Lluveras-Tenorio, R. Vinciguerra, E. Galano, et al., PLOS ONE 12 (4) (2017)

5. M.E.M. Fajardo, M.M. Lopez, A.G. Estrada, Revista de La Facultad de Arquitectura Universidad Autonoma de Nuevo Leon 11 (15), 37 (2017)

6. J. Hladík, Archaeologies 9 (1), 4 (2013)

7. M. Magnani, A. Guttorm, N.Magnani, Journal of Cultural Heritage 31, 162 (2018)

8. I. Djamaluddin Y. Mitani T. Yahara, AASRI Procedia 1, 454 (2012)

9. A.-D. Predescu, G. Triantafyllidis, SHS Web of Conferences 43, 01002 (2018)

10. S. A. Pletneva, Essays on Khazar archaeology (Moscow: "Mosty kul'tury" Publ., 1999)

11. A.A. Corrales, M.J. Bermejo, C.J.M. Campos, Virtual Archaeology Review 9 (18), 77 (2018)

12. A.N. Presnyakova, A.V. Pisarev, S.S. Khrapov, Science J. Volgograd State Unive. Mathematics. Physics. 1 (38) 66 (2017)

13. C. Dostal, K. Yamafune, Journal of Archaeological Science: Reports 18, 430 (2018) 